\title{
Cost-effectiveness Comparison of Coaxial Magnetic Gears with Different Magnet Materials
}

\author{
Mu Chen, K. T. Chau, Fellow, IEEE, Wenlong Li, and Chunhua Liu, Member, IEEE \\ Department of Electrical and Electronic Engineering, The University of Hong Kong, Hong Kong, China
}

\begin{abstract}
This paper presents a comparative study between the non-rare-earth permanent magnet (PM) and rare-earth PM based coaxial magnetic gears. Firstly, by using finite element analysis, the electromagnetic performances of four coaxial magnetic gears which are installed with non-rare-earth PMs or rare-earth PMs are analyzed and quantitatively compared based on the same structure. Then, the natural magnetic properties of non-rare-earth PMs and rare-earth PMs are evaluated and discussed. Finally, the cost-effectiveness of coaxial magnetic gears adopting different types of PMs is assessed. The results indicate that the non-rare-earth PMs, especially the aluminum-nickel-cobalt (Alnico), are preferred for application to coaxial magnetic gears with emphasis on the cost-effectiveness.
\end{abstract}

Index Terms-Magnetic gear, permanent magnet, non-rare-earth, rare-earth, cost-effectiveness.

\section{INTRODUCTION}

$\mathrm{M}$ AGNETIC gears offer the advantages of free of contact, inherent overload capability, silent operation and improved reliability over the traditional mechanical gears [1][5]. They are becoming more and more attractive for various applications such as renewable power generation and electric vehicle propulsion [6]-[8]. They can also be integrated into electric machines to further improve the torque density [9][10]. These attractive characteristics are mainly attributed to the permanent magnet (PM) materials. Nowadays the neodymium-iron-born $(\mathrm{NdFeB})$ and samarium-cobalt $(\mathrm{SmCo})$ are two common types of rare-earth PMs whereas the aluminum-nickel-cobalt (Alnico) and ferrite are two common types of non-rare-earth PMs for application to magnetic gears. In recent years, there are ever-increasing concerns on the price and supply of rare-earth PMs although the rare-earth PMs have better performance. Rare-earth PMs suffer from highly fluctuant supply and very expensive price which hinder their widespread application. In order to overcome the demerits of rare-earth PM materials, non-rare-earth PM materials have received rekindling interest because of their abundant reserves and low price.

The purpose of this paper is to present a comparative study between non-rare-earth PM and rare-earth PM based coaxial magnetic gears. By using the finite element method (FEM), the electromagnetic performances of magnetic gears which are installed with non-rare-earth or rare-earth PM materials are analyzed and compared. Then, the natural magnetic properties of the non-rare-earth and rare-earth PMs are compared. Finally, the cost-effectiveness comparison among different types of PMs is conducted.

\section{Configuration of CoAXial Magnetic Gear}

Fig. 1 shows the configuration of an interior-magnet outerrotor coaxial magnet gear which consists of an inner rotor mounted with surface magnets, a stationary ring and an outer rotor incorporated with interior magnets. The sandwiched stationary ring functions to modulate the PM fluxes between the outer rotor and the inner rotor. The corresponding parameters of this coaxial magnetic gear are given in Table I. The key features of this magnetic gear are summarized as follows [2]:

- Because of the torque amplification effect, the outer rotor needs to withstand a large torque. By burying the PMs with the same polarity into the outer-rotor iron core, the mechanical integrity can be improved.

- The salient teeth next to the PMs in the outer rotor serve as the opposite magnetic poles of the interior PMs. Compared with the conventional coaxial magnetic gear [3], the amount of PM material used and hence the overall cost can be reduced.

In order to conduct a fair comparison, the four coaxial magnetic gears, which are installed with the Alnico, ferrite, $\mathrm{NdFeB}$ and SmCo PM materials, adopt the same topology and the same design criteria:

- same speed of two rotors;

- same yoke length in two rotors;

- same stationary ring;

- same gear ratio;

- same ferromagnetic material used;

- same volume of PMs.

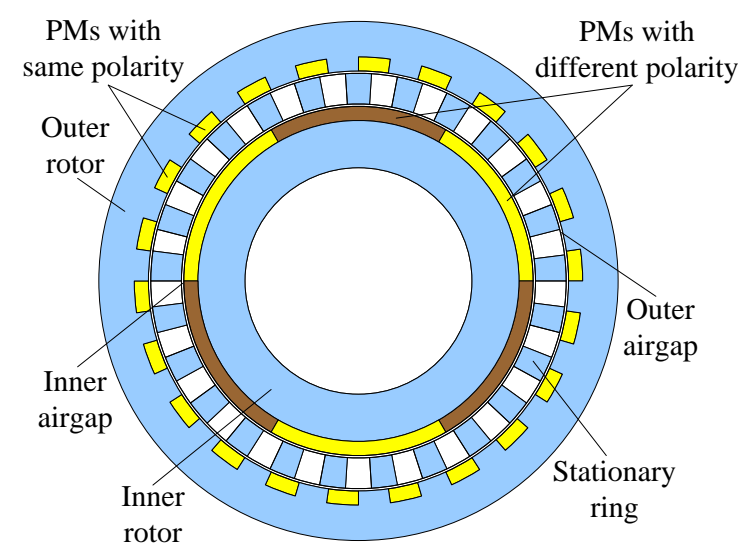

Fig. 1 Configuration of interior-magnet outer-rotor coaxial magnetic gear 
TABLE I

KEY DATA OF COAXIAL MAGNETIC GEAR

\begin{tabular}{ll}
\hline \hline No. of pole-pairs in outer rotor & 22 \\
No. of pole-pairs in inner rotor & 3 \\
No. of iron segments in stationary ring & 25 \\
Thickness of PMs in both rotors [mm] & 6 \\
Length of outer airgap [mm] & 1.0 \\
Length of inner airgap [mm] & 1.0 \\
Outside radius of outer rotor [mm] & 110 \\
Inside radius of outer rotor [mm] & 89 \\
Outside radius of inner rotor [mm] & 74 \\
Inside radius of inner rotor [mm] & 48 \\
Thickness of stationary ring [mm] & 13 \\
\hline \hline
\end{tabular}

\section{Electromagnetic Performance COMPARISON}

By using finite element analysis, the electromagnetic performances of these four magnetic gears are evaluated and quantitatively compared. Firstly, the torque performances and airgap flux density waveforms of the Alnico based magnetic gear are simulated as depicted in Fig. 2 and Fig. 3, respectively. Similarly, the waveforms of the ferrite based magnetic gear are obtained as shown in Fig. 4 and Fig. 5. Thirdly, similar waveforms of the NdFeB based magnetic gear are shown in Fig. 6 and Fig. 7. Fourthly, similar waveforms of the SmCo based magnetic gear are exhibit in Fig. 8 and Fig. 9.

As expected, it is obvious that the rare-earth PMs based magnetic gears have better performance than the non-rareearth PMs based magnetic gears. Firstly, the airgap flux density of rare-earth PM based magnetic gears is significantly stronger than the airgap flux density of non-rare-earth PM based magnetic gears. Secondly, the steady torques developed at the outer rotor and inner rotor of the Alnico based magnetic gear are about $62.15 \mathrm{Nm}$ and $8.45 \mathrm{Nm}$ respectively, which are almost 7 times lower than the torques transmitted by the $\mathrm{NdFeB}$ based magnetic gear which exhibits about $456 \mathrm{Nm}$ and $62 \mathrm{Nm}$. Meanwhile, the steady torques developed at the outer rotor and inner rotor of the ferrite based magnetic gear are about $31.85 \mathrm{~N}$ and $4.35 \mathrm{~N}$ respectively, which are almost 12 times lower than the torques transmitted by the SmCo based magnetic gear which shows about $389 \mathrm{Nm}$ and $53 \mathrm{Nm}$. Thirdly, the torque density of the Alnico based magnetic gear is about $9.29 \mathrm{kN} / \mathrm{m}^{3}$ which is about 7 times and 6 times lower than the torque densities transmitted by the $\mathrm{NdFeB}$ based magnetic gear and the SmCo based magnetic gear respectively which exhibit about $67 \mathrm{kN} / \mathrm{m}^{3}$ and $56 \mathrm{kN} / \mathrm{m}^{3}$. And the ferrite based magnetic gear shows the lowest torque density which is about $4.49 \mathrm{kN} / \mathrm{m}^{3}$. The corresponding torque performance comparison is listed in Table II.

TABLE II

Electromagnetic PeRformance COMPARISON

\begin{tabular}{cccc}
\hline \hline & Outer rotor torque & Inner rotor torque & Torque density \\
\hline Alnico & $62.15 \mathrm{Nm}$ & $8.45 \mathrm{Nm}$ & $9.29 \mathrm{kN} / \mathrm{m}^{3}$ \\
Ferrite & $31.85 \mathrm{Nm}$ & $4.35 \mathrm{Nm}$ & $4.49 \mathrm{kN} / \mathrm{m}^{3}$ \\
$\mathrm{NdFeB}$ & $456 \mathrm{Nm}$ & $62 \mathrm{Nm}$ & $67 \mathrm{kN} / \mathrm{m}^{3}$ \\
$\mathrm{SmCo}$ & $389 \mathrm{Nm}$ & $53 \mathrm{Nm}$ & $56 \mathrm{kN} / \mathrm{m}^{3}$ \\
\hline \hline
\end{tabular}

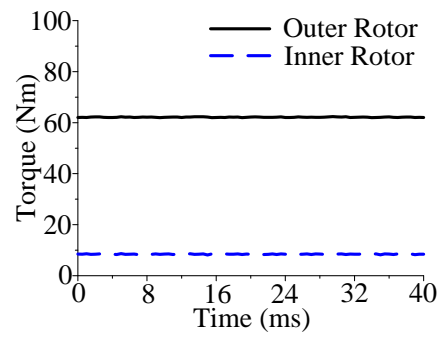

(a)

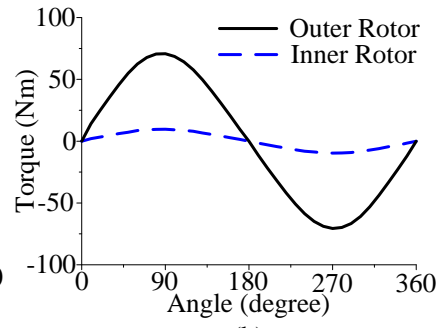

(b)
Fig. 2 Torque waveforms of the Alnico based magnetic gear: (a) Steady torque; (b) Torque characteristics

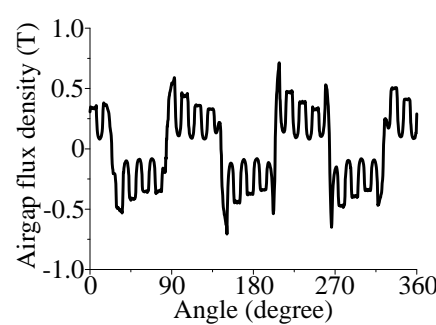

(a)

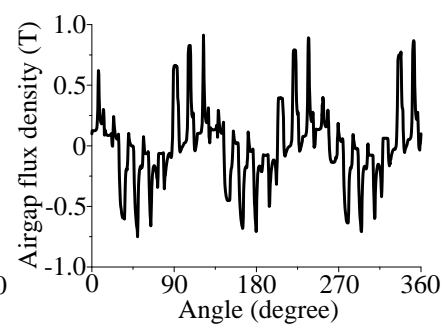

(b)
Fig. 3 Airgap flux density waveforms of the Alnico based magnetic gear: (a) Inner airgap; (b) Outer airgap

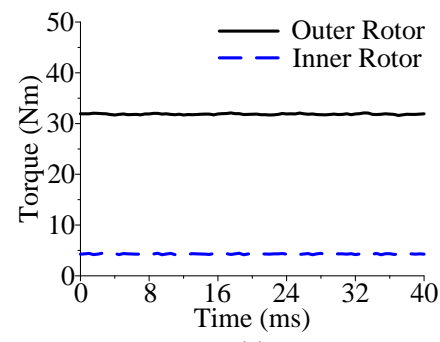

(a)

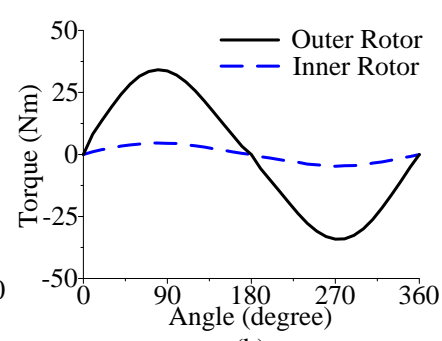

(b)
Fig. 4 Torque waveforms of the Ferrite based magnetic gear: (a) Steady torque; (b) Torque characteristics

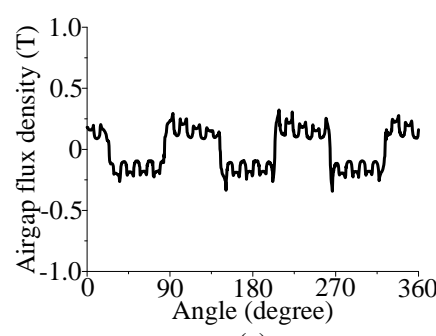

(a)

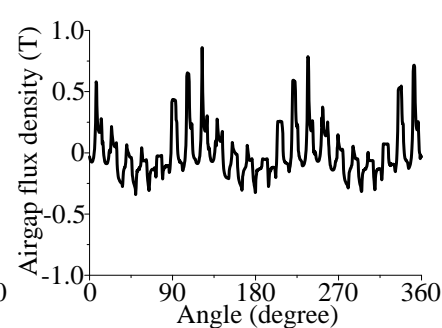

(b)
Fig. 5 Airgap flux density waveforms of the Ferrite based magnetic gear: (a) Inner airgap; (b) Outer airgap

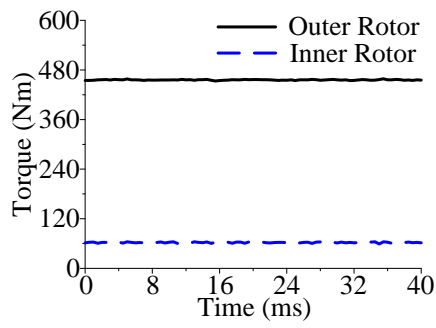

(a)

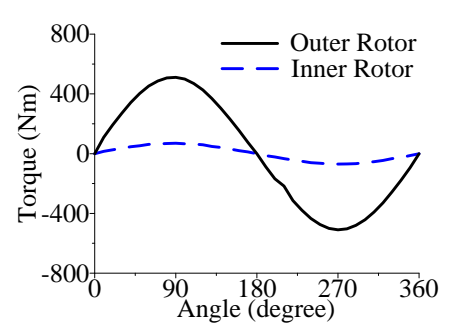

(b)
Fig. 6 Torque waveforms of the NdFeB based magnetic gear: (a) Steady torque; (b) Torque characteristics 


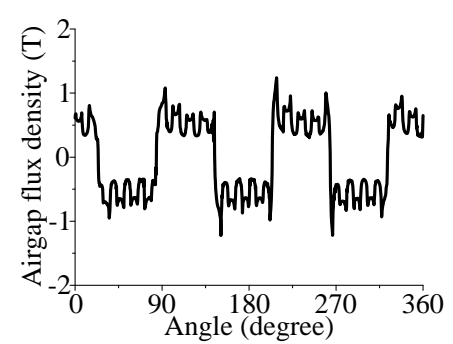

(a)

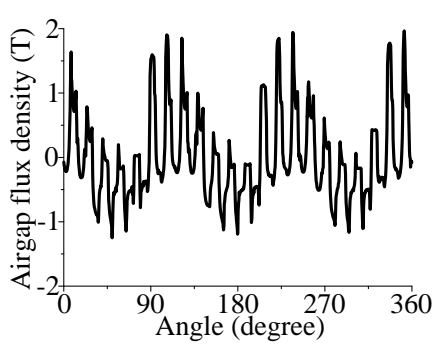

(b)
Fig. 7 Airgap flux density waveforms of the $\mathrm{NdFeB}$ based magnetic gear:

(a) Inner airgap; (b) Outer airgap

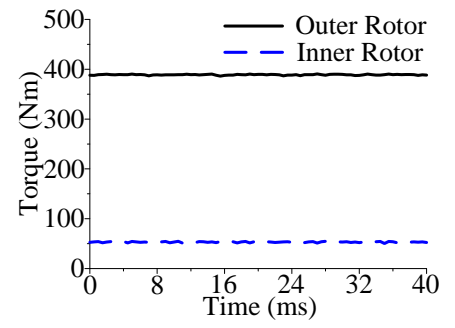

(a)

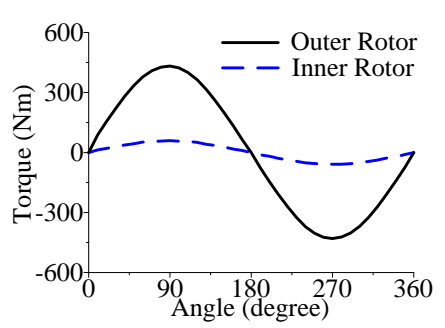

(b)
Fig. 8 Torque waveforms of the SmCo based magnetic gear: (a) Steady torque; (b) Torque characteristics

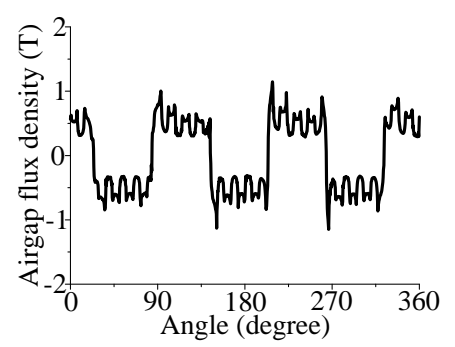

(a)

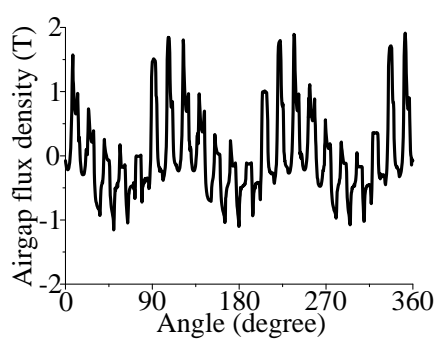

(b)
Fig. 9 Airgap Flux density waveforms of the SmCo based magnetic gear: (a) Inner airgap; (b) Outer airgap

\section{NON-RARE-EARTH AND RARE-EARTH PM COMPARISON}

The electromagnetic performances difference between the rare-earth and non-rare-earth PMs mainly attribute to the natural properties of the PM materials used. Rare-earth PMs, which are developed in the 1970s and 80s, can produce significantly stronger magnetic field than the non-rare-earth PMs. The NdFeB and SmCo are two common types of rareearth PMs which are widely adopted in industrial application.

The $\mathrm{NdFeB}$, which is developed in 1982, is an alloy of $\mathrm{Nd}$, $\mathrm{Fe}, \mathrm{B}$ and other elements such as $\mathrm{Re}, \mathrm{Al}$ and $\mathrm{Cu}$. It offers the advantage of strongest magnetic field whereas low Curie temperature makes it vulnerable in high temperature circumference.

The SmCo, which is the first member of rare-earth PMs, are made of an alloy of Sm, Co and other elements such as Fe and $\mathrm{Cu}$. Although it has the advantages of good temperature stability and high coercivity, it is less adopted than the $\mathrm{NdFeB}$ because of its relatively weaker magnetic field strength and extremely high price.

Although the rare-earth PMs have better performance over other types of PMs, their fluctuant and expensive price as well as finite reserves make them unsuitable for further development in industrial application. The ferrite and Alnico are two common types of non-rare-earth PMs for application of magnetic gear.

The ferrite, which is the most widely used non-rare-earth PM material, consists of ceramic materials with iron oxide. Although it offers the advantage of low price, abundant reserves and high coercivity, its major disadvantage is very low remnant flux density and low maximum energy product.

The Alnico, which is typically composed of $\mathrm{Al}, \mathrm{Ni}, \mathrm{Co}$ and other elements such as $\mathrm{Cu}, \mathrm{Ti}$ and $\mathrm{Fe}$, is a potential candidate to compete with the rare-earth PMs for general application because it offers the merits of very high remnant flux density, extremely high Curie temperature and very low raw material cost. Although the low coercivity makes it vulnerable to demagnetization, this demerit is invalid for magnetic gears or positively utilized because magnetic gears do not involve any armature current [11]. Table III quantitatively compare the natural magnetic properties among these four types of PMs.

TABLE III

MAGNET MATERIAL COMPARISON

\begin{tabular}{ccccc}
\hline \hline & $\mathrm{Hc}(\mathrm{kA} / \mathrm{m})$ & $\mathrm{Br}(\mathrm{T})$ & $\mathrm{BH}_{\max }\left(\mathrm{kJ} / \mathrm{m}^{3}\right)$ & $\mathrm{Tc}\left({ }^{\circ} \mathrm{C}\right)$ \\
\hline Alnico & $40-140$ & $0.6-1.4$ & $10-88$ & $700-860$ \\
Ferrite & $120-300$ & $0.2-0.4$ & $10-40$ & 450 \\
NdFeB & $750-2000$ & $1.0-1.4$ & $200-400$ & $310-400$ \\
SmCo & $600-2000$ & $0.8-1.1$ & $150-240$ & 720 \\
\hline \hline
\end{tabular}

\section{COST-EFFECTIVENESS COMPARISON}

In order to conduct a fair comparison, the raw material prices of these four types of PM materials are considered, while neglecting the product prices which are significantly influenced by many factors such as supply and demand as well as government policy. Their raw material prices can readily be calculated according to the current market prices of individual elements and the chemical compositions of these four PMs. As China is one of the major producers of PM materials, the prices of those elements are based on the Chinese material market in April 2013 as listed in Table IV.

TABLE IV

PRICE OF MAIN ELEMENT

\begin{tabular}{cccc}
\hline \hline Element & Price(USD/kg) & Element & Price(USD/kg) \\
\hline $\mathrm{Ba}$ & 138.6 & $\mathrm{Sr}$ & 7.9 \\
$\mathrm{Al}$ & 3.26 & $\mathrm{Ni}$ & 22.01 \\
$\mathrm{Co}$ & 40.76 & $\mathrm{Sm}$ & 211.97 \\
$\mathrm{Nd}$ & 228.28 & $\mathrm{~B}$ & 4.08 \\
$\mathrm{Cu}$ & 8.64 & $\mathrm{Fe}$ & 0.49 \\
$\mathrm{Re}$ & 2282.77 & & \\
\hline \hline
\end{tabular}

Consequently, the cost of these four magnetic gears can be easily obtained. The steady torque of outer rotor is taken as the key indicator to reflect the cost-effectiveness. Table $\mathrm{V}$ and Table VI summarize the corresponding volume, density, composition, remnant flux density, the steady torque of the 
outer rotor and the resulting cost-effectiveness price. The key is that all the three linear magnetic gears adopt the same volume of PMs $\left(978 \mathrm{~cm}^{3}\right)$. Firstly, it is obviously that the nonrare-earth PM based magnetic gears are more cost-effective than the rare-earth PM based magnetic gears. Although the Alnico based magnetic gear possess low torque output $(62.15 \mathrm{Nm})$, it is most cost-effective. Namely, its costeffectiveness is only $1.197 \mathrm{USD} / \mathrm{Nm}$ which is only $18.2 \%$, $25.3 \%$ and $74.6 \%$ lower than that of the ferrite one $(1.4153$ $\mathrm{USD} / \mathrm{Nm}), \mathrm{NdFeB}$ one (1.5 USD/Nm) and SmCo one (2.09 USD/Nm). Considering the abundant reserves of all required elements for Alnico, it is preferred to the $\mathrm{NdFeB}$ or SmCo to coaxial magnetic gear. Meanwhile, considering the output over the ferrite one, it is also preferred to the ferrite.

Secondly, when the coaxial magnetic gear simply works as a speed reduction or torque amplification device, the Alnico PM materials are free from accidental demagnetization due to the absence of armature winding in magnetic gear, which actually eliminates the key shortcoming of Alnico, namely low coercivity.

Thirdly, due to the Curie temperature of Alnico is extremely high, it makes the Alnico based magnetic gear is preferred to other types of PM based magnetic gears in high temperature circumference.

TABLE V

COST-EFFCTIVENESS COMPARISON (NON-RARE-EARTH PMS)

\begin{tabular}{ccc}
\hline \hline Non-rare-earth PMs & Alnico & Ferrite \\
Volume $\left[\mathrm{cm}^{3}\right]$ & 978 & 978 \\
Density[g/cm & 6.7 & 5 \\
& $8 \%-12 \% \mathrm{Al} ;$ & $\mathrm{BaO} \cdot 6 \mathrm{Fe}_{2} \mathrm{O}_{3}$ \\
& $15 \%-26 \% \mathrm{Ni} ;$ & or \\
Composition & $\begin{array}{c}5 \%-24 \% \mathrm{Co} ; \\
\mathrm{Up} \mathrm{to6} \% \mathrm{Cu}\end{array}$ & $\mathrm{SrO} \cdot 6 \mathrm{Fe}_{2} \mathrm{O}_{3}$ \\
& $\mathrm{Fe}$ (balance) & \\
Br[T] & 1.05 & 0.3 \\
Outer rotor steady & 62.15 & 31.85 \\
torque[Nm] & 9.29 & 4.49 \\
Torque density $\left[\mathrm{kN} / \mathrm{m}^{3}\right]$ & 1.197 & 1.4153 \\
Cost-Effectiveness & & \\
Price[USD/Nm] & & \\
\hline \hline
\end{tabular}

TABLE VI

COST-EFFCTIVENESS COMPARISON (RARE-EARTH PMS)

\begin{tabular}{ccc}
\hline \hline Non-rare-earth PMs & SmCo & NdFeB \\
Volume $\left[\mathrm{cm}^{3}\right]$ & 978 & 978 \\
Density $\left[\mathrm{g} / \mathrm{cm}^{3}\right]$ & 8.4 & 7.5 \\
& $35 \% \mathrm{Sm} ;$ & $29 \%-32.5 \% \mathrm{Nd}$ \\
Composition & $60 \% \mathrm{Co} ;$ & $63.9 \%-68.6 \% \mathrm{Fe}$ \\
& $2.5 \% \mathrm{Fe} ;$ & $1.1 \%-1.2 \% \mathrm{~B}$ \\
Br[T] & $2.5 \% \mathrm{Cu}$ & $0.6 \%-1.2 \% \mathrm{Re}$ \\
Outer rotor steady & 1.0 & 1.1 \\
torque[Nm] & 389 & 456 \\
Torque density $\left[\mathrm{kN} / \mathrm{m}^{3}\right]$ & 56 & 67 \\
Cost-Effectiveness & 2.09 & 1.5 \\
Price[USD/Nm] & &
\end{tabular}

\section{CONCLUSION}

In this paper, the coaxial magnetic gears which are adopted with either rare-earth or non-rare-earth PMs are discussed, with emphasis on electromagnetic performances, PM materials and cost-effectiveness. Four magnetic gears individually adopt the Alnico, Ferrite, NdFeB and SmCo are analyzed by using finite element analysis. Among the four different types of PMs, the rare-earth PM materials based magnetic gears offers better electromagnetic performances than the non-rare-earth PM materials based magnetic gears. Especially the $\mathrm{NdFeB}$ based magnetic gear offers the highest steady torque over others, namely $456 \mathrm{Nm}$ in the outer rotor and $62 \mathrm{Nm}$ in the inner rotor. Although the non-rare-earth based magnetic gears have low output, they offer more cost-effectiveness performances. The Alnico based magnetic gear has the most-cost-effective performance over other types of magnetic gears. Similar results can be obtained when the torque density is taken as the key indicator to reflect the cost-effectiveness. Due to the abundant reserves and lowest material cost as well as the highest cost-effectiveness and free from armature field of magnetic gear and high Curie temperature, the Alnico based magnetic gear is preferred to other types of PM based magnetic gear while the cost-effectiveness is emphasis.

\section{ACKNOWLEDGMENT}

This work was supported by a grant (Project No. HKU 710612E) from the Research Grants Council, Hong Kong Special Administrative Region, China.

\section{REFERENCES}

[1] E. Gouda, S. Mezani, L. Baghli, and A. Rezzoug, "Comparative study between mechanical and magnetic planetary gears," IEEE Transactions on Magnetics, vol. 47, no. 2, pp. 439-450, 2011.

[2] X. Liu, K. T. Chau, J. Z. Jiang, and C. Yu, "Design and analysis of interior-magnet outer-rotor concentric magnetic gears," Journal of Applied Physics, vol. 105, pp. 07F101:1-3, 2009.

[3] K. Atallah, and D. Howe, "A novel high-performance magnetic gear," IEEE Transactions on Magnetics, vol. 37, no. 4, pp. 2844-2846, 2001.

[4] C. C. Huang, M. C. Tsai, D. G. Dorrell, and B. J. Li, "Development of a magnetic planetary gearbox," IEEE Transactions on Magnetics, vol. 44, no. 3, pp. 403-412, 2008.

[5] P. O. Rasmussen, T. O. Andersen, F. T. Jorgensen, and O. Nielsen, "Development of a high-performance magnetic gear," IEEE Transactions on Industry Applications, vol. 41, no. 3, pp. 764-770, 2005.

[6] W. Li, K. T. Chau, and J. Z. Jiang, "Application of linear magnetic gears for pseudo-direct-drive oceanic wave energy harvesting," IEEE Transactions on Magnetics, vol. 47, no.10, pp. 2624-2627, 2011.

[7] L. Jian, K. T. Chau, and J. Z. Jiang, "A magnetic-geared outer-rotor permanent-magnet brushless machine for wind power generation," IEEE Transactions on Industry Applications, vol. 45, no. 3, 2009.

[8] K. T. Chau, D. Zhang, J. Z. Jiang, C. Liu, and Y. J. Zhang, "Design of a magnetic-geared outer-rotor permanent-magnet brushless motor for electric vehicles," IEEE Transactions on Magnetics, vol. 43, no. 6, pp. 2504-2506, 2007.

[9] C. Liu, K. T. Chau, and Z. Zhang, "Novel design of double-stator singlerotor magnetic-geared machines," IEEE Transactions on Magnetics, vol. 48. no. 11, pp. 4180-4183, 2012.

[10] X. Li, K. T. Chau, M. Cheng, and W. Hua, "Comparison of magneticgeared permanent-magnet machines," Progress In Electromagnetics Research, vol. 133, pp. 177-198, 2013.

[11] C. Yu, and K. T. Chau, "Design, analysis and control of DC-excited memory motors," IEEE Transactions on Energy Conversion, vol. 26, no. 2, pp. 479-489, 2011. 